\title{
A educação domiciliar no Projeto de Lei no 2.401/2019 e sua discussão em jornais e revistas veiculadas na web
}

\author{
Maria Celi Chaves Vasconcelos ${ }^{1}$ e Thylara Dantas Pires ${ }^{2}$
}

${ }^{1}$ Faculdade de Educação da Universidade do Estado do Rio de Janeiro, Brasil | maria2.celi@gmail.com | http://orcid.org/0000-0002-3624-4854

${ }^{2}$ Faculdade de Educação da Universidade do Estado do Rio de Janeiro, Brasil | thylarad@gmail.com | https://orcid.org/0000-0002-5739-9919

\begin{abstract}
Resumo: Este estudo visa analisar o Projeto de Lei (PL) no 2.401/2019, do governo Bolsonaro, que trata da temática da educação domiciliar, também conhecida como homeschooling. O objetivo central é apresentar o conteúdo do PL ํㅡ 2.401/2019, buscando verificar como alguns especialistas no assunto se posicionam sobre o tema, por meio de reportagens de jornais e revistas veiculadas na web. Em um plano mais específico examinase como ele pretende estabelecer a educação domiciliar no Brasil, descrevendo as atribuições do estado e as atribuições destinadas às famílias nesta modalidade de educação. Os procedimentos metodológicos remetem a uma investigação qualitativa e exploratória, realizada por meio da pesquisa em sites oficiais do governo, além sites de jornais e revistas disponíveis na internet, cujo marco temporal é o período de janeiro de 2019 a janeiro de 2020 . A escolha da metodologia qualitativa, tendo como fontes principais a exploração de sites oficiais e de sites de notícias de jornais e revistas de grande circulação, revelou-se uma opção adequada para analisar o conteúdo do Projeto de Lei, a partir dos posicionamentos favoráveis e desfavoráveis relativos ao PL elaborado pelo Poder Executivo brasileiro, a fim de cumprir uma promessa de campanha do presidente eleito. Conclui-se que, embora seja importante considerar a demanda das famílias que praticam a educação domiciliar no Brasil, há questões que precisam ser discutidas e incorporadas na regulamentação da matéria, entre elas, aquelas que aparecem nas críticas mais recorrentes ao $\mathrm{PL}$, especialmente às que se referem a como será a supervisão das famílias que praticam a educação domiciliar e qual será a formação exigida para esses pais, uma vez que para ser professor é preciso ter uma formação mínima prevista na legislação vigente.
\end{abstract}

Palavras-chave: Educação Domiciliar; Homeschooling; Projeto de Lei; Regulamentação; Poder Executivo brasileiro.

Home education in Bill nr. 2.401/2019 and its discussion in newspapers and magazines published on the web

\begin{abstract}
This study aims to analyze the Bill of Law (PL) nr. 2.401/2019, of the Bolsonaro government, which deals with the theme of home education, also known as homeschooling The main objective of the present study is to introduce the content of Bill No. 2,401 / 2019, while seeking to verify how some experts look into and take a stand on the subject by means of newspapers and magazines published on the web. On a more specific level, it examines how it is meant to establish home education in Brazil, describing the attributions of the state and the attributions of the families in this type of education. The methodological procedures refer to a qualitative and exploratory investigation, carried out through research on official government websites, in addition to newspaper and magazine websites available on the Internet, whose timeframe is the period from January 2019 to January 2020. The choice of qualitative methodology, having as main sources the exploration of official sites and news sites of newspapers and magazines of great circulation, proved to be an adequate option to understand the content of the Bill, from the favorable and unfavorable positions related to the PL elaborated by the Brazilian Executive Power, to fulfill a campaign promise of the presidentelect. We conclude that, although it is important to consider the demand of families that practice home education in Brazil, there are issues that need to be discussed and incorporated into the regulation of the matter, among them, those that appear in the most recurring criticisms of the PL, especially those that refer to how supervision of families that practice home education will be and what training will be required for these parents, since to be a teacher it is necessary to have a minimum training provided for in the current legislation.
\end{abstract}

Keywords: Home Education; Homeschooling; Bill of Law; Regulation; Brazilian Executive Power. 


\section{Introdução}

O presente trabalho se propõe a uma análise do Projeto de Lei $(P L)$ no 2.401 de 17 abril de 2019, que versa sobre a temática da educação domiciliar, também conhecida como homeschooling, apresentado pelo Poder Executivo ao Parlamento brasileiro, por se tratar de uma promessa de campanha do governo Bolsonaro. O objetivo central é apresentar o conteúdo do PL no 2.401/2019, buscando verificar como alguns especialistas no assunto se posicionam sobre o tema, expondo suas justificativas por meio de reportagens de jornais e revistas veiculadas na web, durante o período de janeiro de 2019 a janeiro de 2020. Em um plano mais específico examina-se como ele pretende estabelecer a educação domiciliar no Brasil, descrevendo as atribuições do estado e as atribuições destinadas às famílias nesta modalidade de educação.

Antes de tratar do Projeto de Lei em si, é necessário conceituar o foco de sua elaboração, a educação domiciliar, ressaltando que ela não é uma novidade no Brasil. A educação domiciliar, de acordo com Vasconcelos (2021, p.195), é "a modalidade de escolarização que ocorre na casa dos alunos, sem a frequência a uma instituição de ensino", sendo realizada sob a responsabilidade dos pais no ambiente doméstico. Contudo, na maioria dos países onde é permitida e regulamentada, as crianças e jovens nesta modalidade devem estar matriculadas em uma escola, e os pais, ao final do período letivo, precisam comprovar que seus filhos receberam educação em conformidade com aqueles que frequentaram a escola.

No Brasil, tal modalidade não encontra na legislação vigente permissão para o seu oferecimento, e este, quando ocorre, baseia-se em uma lacuna, em uma interpretação, em um deferimento judicial, apesar de o Supremo Tribunal Federal (STF), ao julgar a matéria ter considerado que "(...) São inconstitucionais, portanto, as espécies de unschooling radical (desescolarização radical), unschooling moderado (desescolarização moderada) e homeschooling puro, em qualquer de suas variações." (Supremo Tribunal Federal, 2019, n.p.).

Ainda assim, o próprio STF também mostrou qual seria o caminho para a regulamentação: "O ensino domiciliar não é um direito público subjetivo do aluno ou de sua família, porém não é vedada constitucionalmente sua criação por meio de lei federal, editada pelo Congresso Nacional (...)" (Supremo Tribunal Federal, 2019, n.p. - grifo nosso). No entanto, a existência de projetos de lei tentando regulamentar a matéria também não é novidade no país e há três décadas que PLs sobre essa temática circulam pelo Parlamento brasileiro ${ }^{1}$, sendo sucessivamente arquivados. Isso porque, de acordo com Cury (2021, p. 29), "se a Constituição não proíbe a educação no lar, também não permite."

Com a decisão do STF, as "famílias que aderiram à prática perderam a segurança jurídica e precisam da lei" (Coêlho, 2019, p.1). A partir de então, ainda em seu período de campanha eleitoral, no ano de 2018, quando o processo sobre o assunto foi julgado no STF, o atual presidente prometeu, se eleito, editar uma Medida Provisória (MP) sobre a questão. Após assumir a presidência em 2019, o chefe do Poder Executivo afirmou que "em até cem dias de governo" sairia a MP para a regulamentação do ensino domiciliar de crianças em idade escolar, de forma a garantir a proteção aos pais que desejassem ensinar seus filhos em casa, para que não mais estivessem sujeitos às penalidades por não cumprir a Lei $n^{\circ} 12.796$ de 2013, que em seu artigo $6^{\circ}$ determina: "é dever dos pais ou responsáveis efetuar a matrícula das crianças na educação básica a partir dos 4 (quatro) anos de idade". Portanto, os pais que não matriculam seus filhos a partir de 4 anos em escolas regulares, podem responder pelo crime de abandono intelectual, que tem como pena a detenção que varia de quinze dias a um mês ou multa ${ }^{2}$.

1 Trata-se dos Projetos de lei (PL): PL n 4.657/94, PL n 6.001/01, PL n 6.484/02, PL n 4.191/04, PL $n^{0}$ 4.610/04, PL n 3.518/08 e PL $n^{0} 4.122 / 08, P L n^{0} 3.179 / 2012$, Projeto de Emenda constitucional (PEC) $n^{0}$ 444/09), além dos mais recentes, apensados ao PL n³ 3.179/2012.

2 Artigo 246 do Código Penal. Lei 2.848 de 7 de dezembro de 1940. Recuperado de: http://www.planalto.gov.br/ccivil_03/decreto-lei/del2848compilado.htm 
Ao completar cem dias de governo houve a desistência da MP e o governo optou pelo caminho do trâmite legislativo, apresentando uma proposta de Projeto de Lei ao Congresso Nacional. De acordo com o então ministro Onyx Lorenzoni, "a tramitação por Projeto de Lei traria mais segurança às famílias, já que as medidas provisórias correm o risco de perder a validade caso não sejam votadas a tempo pelos parlamentares" ${ }^{3}$. Dessa forma, deu entrada no Parlamento o PL no 2.401/2019, apresentado no dia 17 de abril de 2019 de autoria do Poder Executivo, sendo apensado ao PL que concentra todos os Projetos que tratam dessa mesma matéria, o PL n ${ }^{0} 3.179 / 2012$, que segue aguardando a apreciação conclusiva das Comissões da Casa Legislativa.

\section{Metodologia do Estudo}

No que se refere aos procedimentos metodológicos, trata-se de um estudo qualitativo e exploratório, cujas fontes foram exclusivamente aquelas disponíveis em sites da web, tanto aqueles oficiais do governo quanto de jornais e revistas que tratam da matéria. Além disso, a escolha pelo método qualitativo para a seleção e análise das alusões ao $\mathrm{PL} n$ 2.401/2019 na internet, refere-se ao que assinala Zanette (2017): "o uso do método qualitativo gerou diversas contribuições ao avanço do saber na dinâmica do processo educacional e na sua estrutura como um todo [...]" (p. 159).

Neste sentido, os autores Neri de Souza, Neri de Souza e Costa (2014) alertam para a importância da questão de investigação na pesquisa qualitativa, a qual poderá emergir durante o próprio estudo. Em nossa investigação a questão de partida: "Como os periódicos estão divulgando o $\mathrm{PL}$ nำ 2.401/2019", surgiu também concomitante à exploração das fontes e ao contato com os sites oficiais do governo e dos jornais e revistas que tratavam do $P L$ no 2.401/2019, levando às seguintes indagações complementares: Qual é o conteúdo do PL? Como ele pretende estabelecer a educação domiciliar no Brasil, descrevendo as atribuições do estado e as atribuições destinadas às famílias nesta modalidade de educação? Como os especialistas ouvidos sobre o tema da educação domiciliar posicionam-se sobre o assunto em reportagens veiculadas pela mídia na web, durante o período de janeiro de 2019 a janeiro de 2020? Quais os argumentos mais recorrentes para a aceitação ou a rejeição da proposta?

Aliada ao método exploratório, que pressupõe "proporcionar maior familiaridade com o problema, com vistas a torná-lo mais explícito ou a construir hipóteses" (Silveira e Córdova, 2009, p.35), a pesquisa foi realizada a partir de uma busca minuciosa no site oficial do governo e no acervo digital de cada jornal e revista selecionada que tratou da matéria, o PL no 2.401/2019, a contar de janeiro de 2019 - ano em que Jair Bolsonaro assumiu a presidência da República do Brasil, colocando como uma das prioridades do seu governo a regulamentação da educação domiciliar no país, até janeiro de 2020.

No primeiro momento, a investigação teve como foco a exploração da questão central, fazer o levantamento do conteúdo do PL no 2.401/2019, através da web. Para tanto, dando início à pesquisa exploratória, acessamos os sites governamentais que possuíam notícias sobre o tema, entre eles, o portal do Ministério da Educação (MEC), o site da Câmara dos Deputados, o Senado Notícias e o site do Governo Federal - Ministério da Mulher, da Família e dos Direitos Humanos, totalizando seis reportagens.

A seguir, partimos para a busca de ocorrências sobre o PL em outros sites de mídia disponíveis na internet, tendo como descritor a palavra-chave "educação domiciliar". Como resultado foram verificadas diversas reportagens em cima da temática da educação domiciliar, no intervalo de tempo determinado 2019-2020.

${ }^{3}$ Entrevista com o ministro Onyx Lorenzoni no site Congresso em Foco, 2019, n.p. Recuperado de: https://congressoemfoco.uol.com.br/educacao/educacao-domiciliar-veja-a-integra-do-projeto-de-lei-queo-governo-enviou-ao-congresso/ 
Entre elas selecionamos doze matérias constantes dos sites: a Folha de São Paulo, A Gazeta, o G1 - Educação, a Uol e a Uol Notícias, a Página do Estado, a Gazeta, o R7, o Estudos Nacionais, o Poder 360, a Agência UVA, o 2 em 1 e o Correio Braziliense. No que tange às revistas, foram selecionados sites contendo três matérias na Nova Escola, Claudia, Educação e Crescer.

Ao final do levantamento das matérias foram selecionadas 21 reportagens sobre a temática. Após a leitura exploratória das reportagens, elegemos para análise aquelas que abordavam o PL no 2.401/2019 apresentado ao Parlamento brasileiro no dia 17 de abril de 2019, com a finalidade de regulamentar e legalizar a educação domiciliar no país. Ainda assim, tratava-se de um número expressivo de reportagens, portanto, selecionamos para fazer parte do estudo aquelas que estivessem de acordo com todos os critérios estabelecidos previamente: era necessário que fossem gratuitas, que tratassem sobre 0 Projeto de Lei e que tivessem a palavra-chave educação domiciliar na matéria.

Concluída a seleção final das matérias relativas ao objeto do estudo, foi possível perceber que a $85 \%$ das reportagens foi realizada em abril de 2019, período em que o PL foi assinado pelo presidente e encaminhado pelo Poder Executivo para análise do Congresso Nacional, e que os periódicos citados procuraram especialistas para analisar a medida do governo, em relação à apresentação do Projeto.

Minayo (2016) alerta para o fato de que não podemos esquecer que as "teorias e métodos têm a ver com a realidade do mundo, portanto, seu surgimento e decadência estão articulados historicamente ao desenvolvimento das sociedades". (p.31). Assim, em uma sociedade midiática, na qual os governantes expõem suas opiniões e projetos através das redes sociais, além de usarem as mídias para divulgarem suas prioridades, a escolha da metodologia qualitativa, que tem como fonte privilegiada de pesquisa a exploração de sites oficiais, além de notícias de jornais e revistas de grande circulação, torna-se uma opção adequada para entender os argumentos favoráveis e desfavoráveis sobre o Projeto de Lei elaborado pelo Poder Executivo brasileiro, a fim de cumprir uma promessa de campanha do presidente eleito.

Todavia, a pesquisa através de sites da internet não pode deixar de considerar "as possibilidades e os desafios" que esses modelos de inovação trazem, como indicam Neri de Souza e Bicudo (2016, p. 53). Segundo os autores, ainda que mais viável economicamente, em termos de espaço e tempo; da maior abrangência no campo da pesquisa; do maior número de dados; da diversidade dos dados; da facilidade de organização e armazenamento dos dados no ciberespaço; é preciso questionar o conteúdo e não o tomar como verdade a priori. Como todos os dados, esses colhidos na internet devem ser tratados como depoimentos a serem trabalhados e analisados para que respondam à pergunta inicial do pesquisador e outras que emergirem do estudo. Desta forma, nossa investigação partiu daquilo que recomendam os autores Neri de Souza e Bicudo (2016), com relação ao trabalho com textos retirados da internet, ou seja, começar com questões sobre o objeto: "Qual o tema/problema/pergunta que está em discussão? Como as articulações do pensar exposto no texto são apresentadas e encadeadas? Há fundamentos dos seus porquês? O que diz, o texto, de forma direta e indireta?" (p. 56-57).

Após o "afunilamento" de nossa busca sobre reportagens que tratassem do PL $\mathrm{n}^{\circ}$ 2.401/2019, e a partir dos critérios iniciais delimitados, quais sejam: o intervalo de tempo 2019-2020, que fossem gratuitas, e que tivessem a palavra-chave educação domiciliar na matéria; passamos ao "filtro" dos dados (Neri de Souza e Bicudo, 2016, p.60), selecionando aqueles com maior potencial para a análise e resposta às perguntas de partida: Qual o conteúdo do PL no 2.401/2019 e como ele pretende estabelecer a educação domiciliar no Brasil, descrevendo as atribuições do Estado e as atribuições destinadas às famílias nessa modalidade de educação? Como os especialistas que examinam o tema da educação domiciliar, ouvidos por jornalistas e que registraram suas opiniões nas reportagens, posicionam-se sobre o assunto, evidenciando suas justificativas por meio de jornais e revistas veiculadas na web, durante o período de janeiro de 2019 a janeiro de $2020 ?$ 
Lüdke (2016) chama atenção para o fato de que as pesquisas em educação vão se modificando, "com a introdução e aperfeiçoamento de recursos metodológicos e teóricos, incluindo os trazidos pelas abordagens qualitativas e suas repercussões" (p. 102). Pesquisar em sites disponíveis na internet, procurando identificar, também, em cada um deles sua visão formadora de opinião, é uma significativa abordagem qualitativa, acessada por meio do método exploratório de busca na web, permitindo evidenciar argumentações favoráveis e contrárias não somente à educação domiciliar no Brasil, mas, especialmente, a prioridade do governo brasileiro para educação. Além disso, como afirmam Costa e Neri de Souza (2017), na "investigação qualitativa envolta em diversidade e complexidade de dados não-estruturados e não-numéricos, com determinadas particularidades e subjetividades" (p. 17), é preciso um "olhar" atento do pesquisador para encontrar o seu objeto, analisá-lo e discerni-lo, ainda mais se tratando de pesquisas na mídia.

\section{O PL no 2.401/2019: um Projeto de Governo}

O Governo Federal ao dar entrada do Projeto de Lei ํㅜ 2.401/2019 na Câmara dos Deputados, foi apensado ao PL no 3.179/2012, como ocorre com todos os PLs que tratam do tema da educação domiciliar. Em seu corpo do texto, o primeiro tópico prevê o direito à educação domiciliar no âmbito da educação básica, que deverá ser dirigida pelos pais ou responsáveis, visando ao pleno desenvolvimento da pessoa, seja para o exercício da cidadania ou do trabalho, com base no artigo 5 da Constituição Federal de 1988 em vigor no Brasil. Além disso, estabelece a liberdade de direito de escolha dos pais ou responsáveis sobre o tipo de instrução que será ministrada aos filhos, ou seja, a escolha entre a educação escolar ou a educação domiciliar. Uma vez optando pela segunda, deverá ser assegurado às crianças e aos jovens a convivência familiar e comunitária.

O PL também dispõe sobre a igualdade entre os estudantes da educação escolar e os estudantes do ensino domiciliar, sendo assegurada a participação desses últimos em concursos, eventos, avaliações feitas pelo MEC, incluindo situações que requeiram comprovação de matrícula na escola como requisito para a inscrição.

Além disso, o PL descreve como deverá ser feito o cadastro pela opção da modalidade de educação domiciliar e são informados os documentos necessários para comprovar a identificação dos estudantes e sua filiação ou responsabilidade legal, bem como a residência e o termo assinado de responsabilização por essa opção. São exigidas ainda certidões criminais da Justiça (Federal, Estadual e/ou Distrital), o plano pedagógico individual proposto pelos pais ou responsáveis e, por último, a caderneta de vacinação atualizada. O MEC fará a análise e aprovação para a conclusão do processo de cadastramento na plataforma virtual, plataforma esta que terá o prazo de ficar pronta até 150 dias após a publicação da lei. Contudo, enquanto não estiver disponível a plataforma virtual para a realização do cadastro, as famílias terão assegurado o seu direito de exercer a educação domiciliar.

Contudo, o Projeto de Lei também prevê deveres aos responsáveis que, para terem o direito à escolha da modalidade de educação domiciliar, precisarão cumprir alguns requisitos previstos na regulamentação, a sabe: i) os pais ou responsáveis deverão renovar o cadastro na plataforma com o plano pedagógico individual a cada ano letivo, assim como os demais documentos determinados; ii) os pais ou responsáveis deverão manter também o registro periódico das atividades pedagógicas do estudante para supervisão do MEC, que ainda irá estabelecer como essa etapa será realizada, não havendo no PL, a previsão dos detalhes, e; iii) caberá também aos pais ou responsáveis monitorar o desenvolvimento do estudante durante o processo de ensino e de aprendizagem, conforme a Diretriz Nacional Curricular, já que de acordo com o PL no 2.401/2019, o estudante da educação domiciliar deverá fazer uma avaliação anual, que contará com a gestão do MEC. Essa avaliação terá como referência a Base Nacional Curricular Comum (BNCC) brasileira, com conteúdos relativos ao ano escolar correspondente à idade do aluno, podendo este ter avanço nos cursos e nas séries, conforme o disposto na Lei de Diretrizes e Bases da Educação Nacional (LDBEN). 
Estas avaliações serão aplicadas para estudantes matriculados a partir do segundo ano do ensino fundamental e, preferencialmente, no mês de outubro, podendo ser em outro mês caso o MEC acredite ser mais conveniente. Uma vez que o estudante falte à avaliação, os pais deverão justificar a ausência para que se possa efetuar a avaliação em uma nova data.

Os alunos que tiverem o desempenho insatisfatório na avaliação realizada terão direito à uma prova de recuperação e os alunos que faltarem a essa prova terão que fazer o mesmo processo dos alunos que faltarem à avaliação anual, sendo necessário uma justificativa para poderem efetuar uma nova avaliação de recuperação, com data que será definida pelo MEC.

Importante destacar que é proibido praticar a educação domiciliar por pais ou responsáveis legais que estiverem cumprindo penas por crimes específicos citados no PL. Além disso, os pais ou responsáveis perderão o direito à opção pela educação domiciliar se o estudante for reprovado em dois anos consecutivos ou em três anos não consecutivos e, também, caso não seja justificado o não comparecimento à avaliação anual ou enquanto não for renovado o cadastro anual na plataforma.

No que tange à visibilidade e ao financiamento, o MEC disponibilizará dados referentes à educação domiciliar aos órgãos competentes e, anualmente, decidirá pelas taxas para fins de custeio de avaliação, além de estabelecer as hipóteses de isenção de pagamento; com as despesas ocorrendo de acordo com a dotação orçamentária consignada ao MEC, observados os limites de movimentação, de empenho e de pagamento da programação orçamentária disponível.

\section{Conclusões}

Em abril de 2019, com o envio do PL no 2.401/2019 ao Congresso Nacional, o tema chamou atenção da mídia e gerou bastante repercussão, o que fez com que a maioria dos jornais e revistas desse mais espaço às críticas e defesas tanto do PL, quanto da modalidade de educação domiciliar. Em suas matérias, os periódicos examinados buscaram especialistas para explicar o que era a educação domiciliar e quais os pontos positivos e negativos dessa modalidade, a fim de terem mais argumentos para defendê-la ou atacá-la.

As críticas mais recorrentes nos jornais sobre o PL referem-se em como será a supervisão das famílias que praticam a educação domiciliar e qual será a formação exigida para esses pais, uma vez que para ser professor é preciso ter uma formação mínima. De acordo com o Sindicato dos Servidores do Magistério Municipal de Araucária (SISMMAR) ${ }^{4}$, por exemplo, a MP "possui problemas em diversos pontos" e seria mais uma demonstração de ataque do governo Bolsonaro aos trabalhadores, que são tratados como doutrinadores, demonstrando como a gestão pretende lidar com os problemas relacionados à educação em nosso país.

Outra crítica bastante recorrente, alerta para o fato de que a educação domiciliar não pode ser vista como prioridade de regulamentação no Brasil, como afirma Vasconcelos (2019) "enquanto os ideais e princípios republicanos, entre os quais a universalização da educação, não forem alcançados" (p.1).

${ }^{4}$ SISMMAR - Sindicato dos Servidores do Magistério Municipal de Araucária, coluna retirada do Jornal O Popular no Paraná. Recuperado de: https://sismmar.com.br/site/proposta-de-regulamentar-educacaodomiciliar-e-ataque-aos-trabalhadores-em-educacao/ 
Também como aspecto crítico ressaltado sobre o PL é apontado o alto custo para diplomar um estudante fora do ambiente escolar. Christov (Ongaratto, 2019) assinala que aprovar a educação domiciliar requer um processo bem planejado de avaliação, o que não custa pouco, e este custo acabará sendo pago pela população brasileira, por meio dos impostos, tendo em vista que será um processo custeado pelo MEC. Assim, esse é mais um motivo para o PL não ser tratado como essencial, quando há milhões de pessoas abaixo da linha da pobreza que precisam ser priorizadas.

Por fim, independentemente da decisão que vier a ser tomada no Parlamento brasileiro, é importante lembrar que, mais do que uma posição, o que também está em jogo é o futuro dessas crianças e adolescentes, que têm como direito fundamental a educação escolar e, em caso de regulamentação da educação domiciliar, serão seus pais que tomarão por elas a decisão que irá acompanhá-las por toda a vida. Como assinala Cury (2021), é preciso "insistir na importância do ensino obrigatório na faixa etária prevista em lei, com a devida presença dos alunos em instituições próprias de ensino presencial" (p.37-38), além de valorizar aqueles que lutam por uma educação pública de qualidade.

\section{Referências}

Coêlho, M. (2019). Necessidade de regulamentação da educação domiciliar é apontada em audiência. Agência Senado, 15 out. de 2019, Recuperado de: https://www12.senado.leg.br/noticias/materias/2019/10/15/necessidade-de-regulamentacaoda-educacao-domiciliar-e-apontada-em-audiencia

Constituição da República Federativa do Brasil de 1988. Recuperado de: http://www.planalto.gov.br/ccivil_03/constituicao/DOUconstituicao88.pdf

Congresso em Foco. Educação domiciliar: veja a íntegra do projeto de lei que o governo enviou ao Congresso. Congresso em Foco - Uol, 13 abr. 2019. Recuperado de: https://congressoemfoco.uol.com.br/educacao/educacao-domiciliar-veja-a-integra-do-projetode-lei-que-o-governo-enviou-ao-congresso/

Costa, A. P.; Neri de Souza, F. (2017). Critérios de construção e avaliação de artigos em investigação qualitativa (CCAAIQ). In: A. P. Costa; M. C. Sánches-Gómez; M. V. Martín Cilleros. (Org.). A prática na investigação qualitativa: exemplos de estudos. 1ed. Aveiro - Pt: Editora Ludomedia, v. 1, 17-26.

Cury, C. R. J. (2021). Homeschooling: um desafio legal. In: Vasconcelos, M. C. C. (Org.). Educação domiciliar no Brasil: mo(vi)mento em debate. Curitiba: FAPERJ, CRV.

Lei n. 8.069, de 13 de julho de 1990. Dispõe o Estatuto da Criança e do Adolescente e dá outras providências. Recuperado de: http://www.planalto.gov.br/ccivil_03/leis/l8069.htm

Lei n. 9.394, de 20 de dezembro de 1996. Estabelece as diretrizes e bases da educação nacional. Recuperado de: http://www.planalto.gov.br/ccivil_03/LEIS/L9394.htm

Lei n. 12.796, de 4 de abril de 2013. Altera a Lei no 9.394, de 20 de dezembro de 1996, que estabelece as diretrizes e bases da educação nacional, para dispor sobre a formação dos profissionais da educação e dar outras providências. Recuperado de: http://www.planalto.gov.br/ccivil_03/_Ato2011-2014/2013/Lei/L12796.htm

Lüdke, M. (2016). Educação e pesquisa qualitativa no Brasil. In: Neri de Souza, D.; Costa, A. P; Neri de Souza, F. Investigação qualitativa: inovação, dilemas e desafios. Aveiro-Pt: Editora Ludomedia, v.3, 77-104.

Minayo, M. C. de S. (2016). Fundamentos, percalços e expansão das abordagens qualitativas. In: Neri de Souza, D.; Costa, A. P; Neri de Souza, F. Investigação qualitativa: inovação, dilemas e desafios. Aveiro-Pt: Ludomedia, v.3, 17-48.

Neri de Souza, F.; Bicudo, M. A. V. (2016). Internet e investigação qualitativa, que ameaças e oportunidades? In: Neri de Souza, D.; Costa, A. P; Neri de Souza, F. Investigação qualitativa: inovação, dilemas e desafios. Aveiro-Pt: Ludomedia, v.3, 49-76.

Neri de Souza, F.; Neri de Souza, D.; Costa, A. P. (2014). Importância do questionamento no processo de investigação qualitativa. In: Costa, A. P.; Neri de Souza, F.; Neri de Souza, D. Investigação qualitativa: inovação, dilemas e desafios. Aveiro-Pt: Ludomedia, v.1, 125-146. 
Ongaratto, S. (2020). Ensino domiciliar (homeschooling): entenda o que diz o projeto de lei. Revista Crescer, 16 abr. de 2020, Recuperado de: https://revistacrescer.globo.com/Criancas/Escola/noticia/2019/04/ensino-domiciliar-entendao-que-diz-o-projeto-de-lei.html

Projeto de Lei n. 2.401 de 2019. Dispõe sobre o exercício do direito à educação domiciliar, altera a Lei no 8.069, de 13 de julho de 1990 - Estatuto da Criança e do Adolescente, e a Lei no 9.394, de 20 de dezembro de 1996, que estabelece as diretrizes e bases da educação nacional. Recuperado de:

https://www.camara.leg.br/proposicoes Web/fichadetramitacao?idProposicao=2198615

Silveira D. T.; Córdova, F. P. (2009). A pesquisa científica. In: Gerhardt, T. E.; Silveira D. T. (Org.) Métodos de pesquisa. Porto Alegre: Editora da UFRGS, 31-42.

Supremo Tribunal Federal. (2019). Processo eletrônico público n. de origem: 7052218047 de 2015. Recurso extraordinário em que se discute, à luz dos arts. 205, 206, 208, 210, 214 e 229, da Constituição Federal, a possibilidade de o ensino domiciliar (homeschooling) ser proibido pelo Estado ou viabilizado como meio lícito de cumprimento, pela família, do dever de prover educação. Recuperado de:

http://stf.jus.br/portal/jurisprudencia/listarJurisprudencia.asp?s1=\%28RE\%24\%2ESCLA\%2E+ $\mathrm{E}+888815 \% 2 \mathrm{ENUME} \% 2 \mathrm{E} \% 29+\mathrm{OU}+\% 28 \mathrm{RE} \% 2 \mathrm{EACMS} \% 2 \mathrm{E}+\mathrm{ADJ} 2+888815 \% 2 \mathrm{EACMS} \% 2 \mathrm{E}$ $\% 29 \&$ base=baseAcordaos\&url=http://tinyurl.com/qgofqvk

Vasconcelos, M. C. C. (2021). (Org.). Educação domiciliar no Brasil: mo(vi)mento em debate. Curitiba: FAPERJ, CRV.

Vasconcelos, M. C. C. (2019). Educação domiciliar deve ser reconhecida no país? A Gazeta, 0510-2019, 1a., GUIA DO ENSINO-EV-Especial Revista-3. Recuperado de: https://especiais.gazetaonline.com.br/guiadoensino/2019/educacao-domiciliar-deve-serreconhecida-no-pais/

Zanette, M. S. (2017) Pesquisa qualitativa no contexto da Educação no Brasil. Educar em Revista, Curitiba, Brasil, n. 65, p. 149-166, jul./set. 2017. Recuperado de: https://doi.org/10.1590/0104-4060.47454. doi: 10.1590/0104-4060.47454 